\title{
A VIRTUALIDADE COMO PROCESSO DE COMUNICAÇÃO E COMPLEXIDADE NA EDUCAÇÃO DE ENSINO SUPERIOR PRESENCIAL.
}

\author{
Antônio Carlos da CONCEIÇÃO FILHO ${ }^{1}$ \\ Universidade Federal do Amazonas - Manaus - AM \\ Denize PICCOLOTTO Carvalho ${ }^{2}$ \\ Universidade Federal do Amazonas - Manaus - AM \\ Núbia Silva NAJAR ${ }^{3}$ \\ Universidade Federal do Amazonas - Manaus - AM
}

\section{RESUMO}

O presente trabalho intitulado "A virtualidade como processo de comunicação e complexidade na educação de ensino superior presencial" tem por objetivo principal apreciar e avaliar a utilização das ferramentas na modalidade EaD e sua utilização no processo comunicacional no Ensino superior presencial, a metodologia utilizada será a qualitativa onde serão utilizadas ferramentas como questionários, entrevistas e observação direta, pretende-se através desta pesquisa abordar as mudanças que a EaD tem proporcionado aos acadêmicos de ensino superior modalidade presencial, em seus processos de aprendizado a partir das questões de âmbito comunicacional e ecossistêmico, além de chamar a atenção para as questões norteadoras neste processo aparentemente novo ao acadêmico. Como resultados esperados pretende-se demonstrar que a tecnologia tem mudado com o passar dos anos, e essas mudanças interferem diretamente no que podemos chamar de era digital, onde a virtualização de processos e atividades tem criado paradigmas e questões complexas e, que cabe a instituição, professor e aluno adaptar-se a essas mudanças, de forma tal que a comunicação seja observada como objeto de estudo neste meio complexo: o educacional.

PALAVRAS CHAVE: Comunicação, Complexidade, Virtualidade, EaD, Ensino Superior Presencial.

\section{ABSTRACT}

\footnotetext{
${ }^{1}$ Administrador de Empresas, Mestrando em Ciências da Comunicação - UFAM - Programa de Pós Graduação em Ciências da Comunicação - PPGCCOM Pesquisador de Comunicação e EaD, e-mail : admcarlostirelli@hotmail.com

${ }^{2}$ Professora do Depto. de Artes e do Programa de Pós-Graduação em Ciências da Comunicação da Universidade Federal do Amazonas (UFAM); Pós-doutora em Tecnologia Educacional e Doutora em Educação pela Universitat de les Illes Balears (UIB); Mestre em Educação (UFAM); Mestre em Tecnologia Educacional (UIB); Atua nos GPs: Estudos e Pesquisas em Arte e Tecnologia Interativa (líder); Tecnologia Educacional (pesquisador); Ciência da Comunicação, Informação Design e Artes (pesquisador) e Conteúdos Digitais (pesquisador), e-mail: piccolotto.levy@gmail.com.

3 Professora do Depto. de Artes e da Educação a Distância da Universidade Federal do Amazonas (UFAM);Especialista em Tecnologia Educacional e Doutoranda em Educação pela Universitat de les Illes Balears (UIB); e-mail: nubia.najar@gmail.com.
} 
This work titled "Virtuality as a process of communication and complexity in attendance higher education" is primarily engaged in assessing and evaluating the use of tools in distance education mode and its use in the communication process in the face of Higher the methodology used will be the quality which will be used tools such as questionnaires, interviews and direct observation, it is intended through this research address the changes that distance education has provided academic higher education face modality in their learning processes from the issues of communication and ecosystem level, as well as draw attention to the guiding questions in this seemingly new to the academic process. As expected results it is intended to demonstrate that technology has changed over the years, and these changes directly interfere in what we call digital era where virtualization of processes and activities has created paradigms and complex issues, and that fits the institution, teachers and students adapt to these changes, such that communication is seen as an object of study in this complex environment: the education.

KEYWORDS: Communication, Complexity, Virtuality, Distance Education, Higher Education Classroom.

\section{RESUMEN}

El presente trabajo que se intitula: "La virtualidad como proceso de comunicación y complejidad en la educación de La enseñanza superior presencial" tiene por objetivo principal apreciar y evaluar la utilización de las herramientas en la modalidad EaD y su utilización en el proceso comunicacional en la enseñanza superior presencial , se va a utilizar la metodología cualitativa donde se van utilizar herramientas como cuestionarios, entrevistas y observaciones directas, pretende-se a través de esta investigación abordar los cambios que la $\mathrm{EaD}$ tiene proporcionado a los académicos de la enseñanza superior modalidad presencial, en sus procesos de aprendizaje a partir de las cuestiones de ámbito comunicacional y eco sistémico, además de chamar la atención para las cuestiones orientadoras en ese proceso aparentemente nuevo al académico. Como resultados esperados pretende-se demonstrar que a tecnología tiene mudado con el pasar dos anos, y estos cambios interfieren directamente no que podemos chamar de era digital, donde la virtualización de procesos y actividades tienen creado paradigmas y cuestiones complejas y, que cabe a la institución, profesor y alumno adaptarse a estos cambios, de forma tal que la comunicación sea observada como objeto de estudio en ese medio complejo: el educacional.

PALABRAS CLAVE: Comunicación, Complejidad, Virtualidad, EaD, Enseñanza Superior Presencial.

\section{INTRODUÇÃO}

O mundo, o homem e a sociedade, passam por mudanças que os acompanham de maneira que tudo ao seu redor se relaciona, direta ou indiretamente. Não é à toa que surgiram termos, como: Globalização, Era da Informação, Tecnologia, Redes Sociais, etc. A rotina de todos que convivem com 
pessoas ou máquinas é modificada, abandonando-se uma visão mais humana para entrar-se no mundo "Hi tech", onde tudo é tecnológico e digital, e a dependência da rede mundial de computadores (Internacional-Networking ou apenas InterNet) passa a ter extrema importância em qualquer processo. Seja ele produtivo, tecnológico ou humano, seu uso é essencial. (Garcia, 2003). A atualidade nos impõe maneiras diferentes de nos relacionarmos devido ao grande crescimento populacional que nos direciona às mais variadas formas e meios de comunicação, pois a distância e a tecnologia permitem nos adaptarmos de maneira rápida e versátil.

O primeiro autor a denominar o momento atual de Era da Tecnologia foi Drucker (1946), expondo esse novo paradigma social que está causando alterações e um crescimento exponencial da comunicação e dos meios, sendo utilizados muitos recursos e ferramentas que provocam uma revolução digital.

Não fazemos apenas o uso do telefone móvel ou das mensagens (os chamados SMS), também utilizamos outras ferramentas como WhatsApp, Messenger, Line, etc. Ao mesmo tempo, estamos mais "próximos" uns dos outros pela internet e suas redes sociais, através de ferramentas instaladas em nosso aparelho celular que proporcionam comunicação sincrônica e assincrônica conectadas à rede, e que nos causam sensação de proximidade extrema. De forma paradoxal, separa-nos, pois, atualmente, os meios de comunicação utilizados por jovens, crianças, adultos e idosos proporcionam também um distanciamento.

Podemos dizer, portanto, que temos novas atribuições e que isso, como nos coloca Levy (2010) pertence ao novo estado da inteligência coletiva. Desse modo, a inteligência coletiva, na visão do referido autor:

\footnotetext{
É uma inteligência distribuída por toda parte, incessantemente valorizada, coordenada em tempo real, que resulta em uma mobilização efetiva das competências. (...) a base e o objetivo da inteligência coletiva são o reconhecimento e o enriquecimento mútuos das pessoas, e não o culto de comunidades fetichizadas ou hipostasiadas. (Levy, 1999, p.28-29).
}

Portanto, podemos vislumbrar o quanto a sociedade tem alterado sua rotina e meios de lidar com diversos atributos e até valores que não se mensuram, como a proximidade que uma rede social estabelece. O paradoxo da distância se torna efetivo, uma vez que, é praticamente impossível estar junto sem estar distante, ou no caso da educação, em que muitas vezes a acessibilidade é melhor através de 
modelos semipresenciais ou totalmente a distância. Nesse sentido, observamos que o ensino presencial torna-se cada vez mais precário, já que exige frequência e deslocamento diários.

Este artigo tem como foco evidenciar a Educação a Distância (EaD) e o seu papel na sociedade contemporânea, através do estudo da virtualização das disciplinas no modelo semipresencial, pois entendemos ser necessário adaptar-nos aos modelos e padrões que estão sendo impostos nessa modalidade de ensino, especificamente no ensino superior presencial. Também é nosso objetivo demonstrar a comunicação como um sistema complexo, no que tange à virtualização de disciplinas, e compreendê-la como aliada das formações educacional e comunicacional do indivíduo.

Para tanto, nesta pesquisa, baseamo-nos numa abordagem qualitativa, por nos permitir uma interação e o contato face a face com os sujeitos participantes no decorrer do tempo. Nosso objeto de análise é a virtualização das disciplinas no modelo semipresencial de ensino superior e, com nosso problema estabelecido, pretendemos investigar como ocorre o processo de comunicação e aprendizagem no modelo semipresencial do ensino superior.

Compreendemos que a pesquisa qualitativa, por ser "um meio para explorar e para entender o significado que os indivíduos ou grupos de indivíduos atribuem a um problema social ou humano" (Creswell, 2010, p.26) permite-nos uma abordagem que "parte do fundamento de que há uma relação dinâmica entre o mundo real e o sujeito, uma interdependência viva entre o sujeito e o objeto, um vínculo indissociável entre o mundo objetivo e a subjetividade do sujeito". (Chizzotti, 2003, p. 79).

De acordo com Creswell (2010), realizaremos neste estudo uma pesquisa-ação participativa que incluirá observação direta, aplicação de questionários e realização de entrevistas. Esperamos, a partir de comparações entre os modelos presencial e semipresencial, detectar a complexidade da comunicação e sua influência na educação.

Já para Thiollen (2004) a pesquisa-ação não é considerada como uma metodologia, e sim um método ou uma estratégia de pesquisa agregando vários métodos ou técnicas de pesquisa social. Ao utilizar-se estas técnicas se estabelece uma estrutura coletiva, participativa e ativa ao nível de captação de informação, o 
que pretendemos ao observarmos de forma direta os modelos presencial e semipresencial de educação oferecidos pela IES estudada.

Portanto, propondo soluções quando for possível e acompanhar ações correspondentes, ou pelo fazer progredir a consciência dos participantes quando se trata da existência de soluções e de barreiras.

\section{O PROCESSO DE COMUNICAÇÃO NO ENSINO SUPERIOR PRESENCIAL}

Na educação, há uma crise em todos os níveis de ensino, do fundamental ao superior, devido à maneira desgastada e do excesso de disciplinas desenvolvidas em sala de aula, muitas vezes lotada e com didáticas defasadas, fazendo com que os alunos tenham dificuldade de assimilar o que está sendo transmitido.

Como afirma Morin (2003) a educação, como utilização de meios, permite assegurar a formação e o desenvolvimento do ser humano; e o ensino, como arte ou ação de transmitir conhecimentos ao aluno, de modo que os compreenda e assimile, ou seja, a função que a educação tem, para quem está inserido neste contexto educacional, é desenvolver suas habilidades como ser humano e nortear os preceitos e formação pedagógica do indivíduo. Ela deve seguir de forma diferenciada, considerando o que observamos na educação tradicional.

O ensino superior tem passado por mudanças nos campos econômicos, sociais e tecnológicos, que fazem com que este estudo seja visto como objeto da comunicação, pois, quando se transforma ou muda a maneira tradicional do que se faz, certamente irá influenciar o processo de comunicação. Como afirma Castells:

\footnotetext{
Surge uma nova sociedade quando e se uma transformação estrutural puder ser observada nas relações de produção, de poder, e de experiência. Essas transformações conduzem a uma modificação também substancial das formas sociais de espaço e tempo e ao aparecimento de uma nova cultura. (Castells, 1999, p. 416).
}

Entendemos que romper com um modo didático tradicional requer certa cautela com as questões sociais formadas em um mundo material e também requer a disposição de novas ferramentas e aplicabilidades para os adventos digitais. 
Segundo Gabriel (2013, p.35) "a educação tem duas fases a Era Pré-digital, em que o professor é detentor do conteúdo e funcionava como filtro para os alunos, e a Era Digital, na qual ele perde a função quando os alunos passam a ter acesso a todo tipo de conteúdo e informação". Portanto, presumimos que a Era Pré-digital ainda predomine nas instituições de ensino superior, que resistem com o modo tradicional de ensino, pois se utilizar da tecnologia como recurso didático requer mudanças, as quais geram inquietações tanto nos acadêmicos, como nos professores; além de exigir um tempo a mais de aprendizado das atuais ferramentas, e de como gerar esse estímulo para que seja motivador para as duas partes.

O fato é que a comunicação tem evoluído com o decorrer dos anos, no entanto, o ensino e a aprendizagem, e o meio pelo qual eles se utilizam para chegar aos estudantes, não conseguem, por vários fatores, adequar-se ao atual processo comunicacional, que inicia na própria instituição e termina no aluno. Como afirma Marchiori (2003, p. 89) "a comunicação tem como essência nutrir relações, os processos, por conseguinte, instituem-se e ganham significação sendo naturalmente compreendido pelas pessoas, afinal, são elas que participam desta construção". Sendo assim, a comunicação, como objeto de estudo, é observada, nesse contexto, como parte primordial no processo educacional.

Podemos afirmar que não há educação sem comunicação e vice-versa. Há de se convir que os fatores implicantes diretamente no processo de ensinoaprendizagem influem na comunicação.

Relembramos que, desde o ensino básico, algumas instituições ensinam de forma disciplinar sem possibilitar adaptações às mudanças que nos proporcionam a Era Digital. Assim, essa forma de ensino conserva o "velho modo" de transmitir educação, ou seja, o professor tem o papel de apenas passar o conteúdo, de forma que não se criam maneiras mais práticas e versáteis de utilizar a comunicação como processo de ensino. Conforme Morin (2003):

Estamos vivendo em uma nova fase da educação, onde tudo está fragmentado e interfere no processo educacional, e gera a inteligência cega, a construção do conhecimento na ciência, opera por princípios reducionistas (que associa o que é diferente), de disjunção (que separa e distingue o que está ligado), de hierarquização, de centralização e de abstração. (Morin, 2003, p. 123). 
Em um contexto mais amplo, focado na educação, o autor destaca o quanto é importante desenvolver métodos e práticas mais eficazes no processo educacional, é nesse sentido que o referido intelectual afirma que a missão do ensino não é transmitir o mero saber, mas uma cultura que permita compreender nossa condição e nos ajude a viver favorecendo, ao mesmo tempo, um modo de pensar aberto e livre. O professor exerce um papel essencial nesse atual mundo digital, não mais como um "provedor de conteúdos", mas funcionando como um catalisador de reflexões e conexões para seus alunos nesse ambiente mais complexo, que também é mais rico e poderoso. (Gabriel, 2013).

Entendemos que o professor sempre fará parte do processo educacional, por mais que esse processo evolua e se aperfeiçoe, pois sempre se necessitará de um intermediador, um direcionador, um orientador.

\begin{abstract}
As novas tecnologias tanto podem auxiliar como atrapalhar nos processos educacionais, a sua mera presença em si não é uma vantagem, mas o apropriado, o fato de uma escola ou universidade possuir laboratórios não torna a educação melhor ou pior, o que vai determinar a qualidade da educação é como esse laboratório é utilizado por alunos e professores, na mesma linha de raciocínio o fato dos alunos terem tablets e acessarem a internet durante as aulas pode tanto ser positivo quanto negativo dependendo do tipo e do objetivo de acesso a internet e de sua relação com os conteúdos educacionais da sala de aula. (Gabriel, 2013, p.12).
\end{abstract}

Isso demonstra que cabe ao professor detectar, em sala de aula, os recursos e ferramentas necessárias para fomentar uma metodologia tecnológica capaz de despertar o interesse dos acadêmicos por buscar o conhecimento cientifico a partir de pressupostos e diretrizes oriundos da 'nova era' da educação no ensino superior presencial.

\title{
2 A COMUNICAÇÃO NA EaD
}

A fase da educação atual é promissora e sua base está na comunicação. De maneira geral, podemos dizer que, no ato da comunicação, não utilizamos somente um conjunto de palavras faladas ou escritas, mas também imagens, gestos, ferramentas digitais. (Terra, 1997). No decorrer dos últimos anos, grandes 
mudanças têm sido impostas à sociedade, isso é devido aos avanços tecnológicos que se tornaram parte das rotinas laborais e educacionais.

De fato, o uso de tecnologias nos processos de comunicação possibilita uma melhor pulverização do conteúdo (conteúdo em sala e em outros ambientes externos à escola), o que contribui para um ganho de aprendizado. Isso se insere no novo modelo de educação, a EaD. Acerca desse fato, Lévy (1999) afirma que, atualmente, toma-se consciência dos novos paradigmas para aquisição de conhecimento e para construção dos saberes, os quais se direcionam para um sistema pedagógico que propicie a construção de trajetórias e percursos de aprendizagem, através da participação ativa do aluno de uma transição de informação num tempo e espaço flexível, já que a educação flexível está relacionada tanto com o uso aberto da tecnologia, como com o conhecimento desenvolvido durante essa evolução tecnológica.

Pretti (1996) acrescenta que a Educação a Distância é, pois, uma modalidade não-tradicional, típica da era industrial e tecnológica, cobrindo distintas formas de ensino-aprendizagem, dispondo de métodos, técnicas e recursos, postos à disposição da sociedade. Denotando que, com o passar dos anos, a aprendizagem vai se aperfeiçoando e se adaptando com a evolução tanto da tecnologia, como dos métodos educacionais cada vez mais flexíveis.

Maia e Mattar (2002) afirmam que, a partir da invenção da impressa, no século $\mathrm{XV}$, foi permitido um maior acesso a informação, facilitando o processo de divulgação de ideias e democratizando o conhecimento, dessa forma, se potencializou as reformas e revoluções sem a necessidade de um narrador presente, favorecendo também a EaD, já que ela se processa nesse cenário de espaço e tempo diferenciados.

Gabriel (2013) define a internet como fenômeno de hiperconexão, que não acontece somente em rede, mas alcança também as pessoas, os sistemas e as máquinas. Com o surgimento e a popularização de equipamentos altamente tecnológicos que geram uma facilidade maior em questões como conexão, comunicação e compartilhamento, acontecem mudanças significativas para a internet e a web. Portanto, essas melhorias na parte técnica corroboram para uma educação de qualidade e dentro dos padrões atuais, embora muitas vezes isso não aconteça como se espera. Segundo Gabriel (2013) as mudanças da internet e da web podem se definir da seguinte maneira, a Web 1.0 é a estática, em que as 
pessoas apenas navegam e consomem informações. Ela foi predominante até o final do século XX. Já a Web 2.0:

\begin{abstract}
É a web da participação, em que as pessoas usam a web como base para todo tipo de interação: blogs, vídeos, fotos, redes sociais. Ela funciona como uma plataforma participativa de serviços, por meio da qual não apenas se consomem conteúdos, mas principalmente se colocam conteúdos, a web 2.0 é também o que chamamos de computação na nuvem - os aplicativos (como Gmail, redes sociais, etc.) ficam na internet e só são acessados por meio de computadores com conexão on-line. (Gabriel, 2013, p.23).
\end{abstract}

E por fim a autora coloca que "a web 3 ou web semântica , além da informação em si, o contexto e as ligações referentes a essa informação permitem encontrar um significado que auxilie o uso da web, conforme a web 3.0 avança , as plataformas digitais passam a ser cada vez mais sensíveis a contexto (localização, personalização, dispositivo etc.)". (Gabriel, 2013, p.24).

Através das mudanças advindas das diferentes formas de web, deu-se início a uma participação mais integrada e participativa dos usuários em rede. Com esses avanços, notamos que a participação de professor e de aluno começou a tomar outros rumos que implicam diretamente a comunicação e como ela tem sido passada, propiciando-nos meios diferentes de usar a tecnologia em seu contexto mais amplo e prático. Fato que ocorre na EaD que, segundo Landim (1997) "é o processo de ensino-aprendizagem, mediado por tecnologias, onde professores e alunos estão separados espacial e/ou temporalmente". Ou seja, é o processo de ensino-aprendizagem em que professores e alunos não estão normalmente juntos, fisicamente; mas podem estar conectados, interligados por tecnologias, principalmente as telemáticas, como a internet, e utilizando ferramentas como o correio, o rádio, a televisão, o vídeo, o CD-ROM, o telefone, o fax, entre outras.

Portanto, as plataformas de aprendizagem, mídias sociais e os recursos tecnológicos, de um modo geral, levam com praticidade e comodidade o aprendizado ao seu público-alvo, o que, sem sombra de dúvidas, gera um novo tempo de recursos comunicacionais inseridos nos processos de avaliação, didática e educacional. Os recursos didáticos cada vez mais tecnológicos exigem uma rápida adaptação dos acadêmicos. No Ambiente Virtual de Aprendizagem (AVA), o acadêmico se dispõe a aprender de maneira autônoma, ou seja, estudando de forma independente, transformando um conceito de auto-formação e de desenvolvimento 
da habilidade de leitura e interpretação textual autônoma. Os estudos midiatizados constituem um momento de interação feito com o uso de meios de comunicação, como a internet. Através do seu login e senha, o acadêmico acessa e interage para angariar conhecimento. Tendo em vista que as grandes instituições estão aderindo a esse tipo de modalidade de ensino, acreditamos que deve haver uma maior preocupação com os meios de comunicação utilizados para avaliar e se realmente há o retorno esperado.

\section{A COMUNICAÇÃO E A COMPLEXIDADE NO PROCESSO DE VIRTUALIADADE.}

A complexidade e suas implicações são as bases do denominado pensamento complexo de Morin (2010), que vê o mundo como um todo indissociável e propõe uma abordagem multidisciplinar e multi-referenciada para a construção do conhecimento. Contrapõe-se à causalidade linear por abordar os fenômenos como totalidade orgânica. Segundo Morin (2010):

\footnotetext{
À primeira vista, a complexidade é um tecido de constituintes heterogêneos inseparavelmente associados: coloca o paradoxo do uno e do múltiplo, mas então a complexidade apresenta-se com os traços inquietantes da confusão, do inextricável, da desordem no caos, da ambigüidade, da incerteza. Daí a necessidade, para o conhecimento, de pôr ordem nos fenômenos ao rejeitar a desordem, de afastar o incerto, isto é, de selecionar os elementos de ordem e de certeza, de retirar a ambigüidade, de clarificar, de distinguir, de hierarquizar. (Morin, 2011, p.125).
}

Entendendo que a complexidade é dada e inserida em um processo, seja ele de qualquer dimensão ou segmento, deparamo-nos com os paradigmas, porque, em se tratando de educação propriamente dita, as pessoas estão acostumadas a uma maneira clássica e padronizada de educar e, quando se deparam com a mudança e a inserção da tecnologia como parte integrada da educação, os dilemas e preconceitos vêm à tona. Isso é complexidade, pois a ordem está na desordem.

A introdução de Tecnologias de Informação e Comunicação (TIC) na educação, principalmente associadas ao uso do computador, provocou mudanças no paradigma educacional, ou seja, o foco foi deixando de ser o ensino e passou a centrar-se no aluno e na sua aprendizagem. O processo de virtualização no ensino presencial está sendo inserido e demonstra esses dilemas. 
Como afirma Lemos (2013, p.161, grifo do autor) "o processo de virtualização pode ser entendido como um questionamento de deslocamento do 'aqui e agora', que compõe toda a realidade e toda experiência e, nesse sentido a realidade é constituída no processo interminável de atualizações e virtualizações sucessivas".

Afinal, os paradigmas criados em torno do processo de virtualização, seja ele de disciplinas ou atividades inerentes, que irão agregar ao processo de ensino aprendizagem, geram uma inquietação aos acadêmicos, professores e a organização em si. Como afirma Lemos (2013) a virtualização, no seu sentido telemático ou informático, traz à baila questões relativas à desrealização da experiência e também o medo correlato da perda do contato com o real. Como vemos a partir da edição de algumas resoluções que regulamentam esse tipo de modalidade, criaram-se novas metodologias a serem seguidas. Podemos ver na Resolução № 2, de 18 de Junho de 2007, que dispõe o seguinte:

\begin{abstract}
Art. $2^{\circ}$ - As Instituições de Educação Superior, para o atendimento do art. $1^{\circ}$, deverão fixar os tempos mínimos e máximos de integralização curricular por curso, bem como sua duração, tomando por base as seguintes orientações: I - a carga horária total dos cursos, ofertados sob regime seriado, por sistema de crédito ou por módulos acadêmicos, atendidos os tempos letivos fixados na Lei $n^{\circ} 9.394 / 96$, deverá ser dimensionada em, no mínimo, 200 (duzentos) dias de trabalho acadêmico efetivo; II - a duração dos cursos deve ser estabelecida por carga horária total curricular, contabilizada em horas, passando a constar do respectivo Projeto Pedagógico; III - os limites de integralização dos cursos devem ser fixados com base na carga horária total, computada nos respectivos Projetos Pedagógicos do curso, observados os limites estabelecidos nos exercícios e cenários apresentados no Parecer CNE/CES $n^{\circ} 8 / 2007$, da seguinte forma: a) Grupo de Carga Horária Mínima de 2.400h: Limites mínimos para integralização de 3 (três) ou 4 (quatro) anos. b) Grupo de Carga Horária Mínima de 2.700h: Limites mínimos para integralização de 3,5 (três e meio) ou 4 (quatro) anos. c) Grupo de Carga Horária Mínima entre 3.000h e 3.200h: Limite mínimo para integralização de 4 (quatro) anos. d) Grupo de Carga Horária Mínima entre 3.600 e 4.000h: Limite mínimo para integralização de 5 (cinco) anos. e) Grupo de Carga Horária Mínima de 7.200h: Limite mínimo para integralização de 6 (seis) anos. (Brasil, Resolução № 2/2007).
\end{abstract}

Após essa regulamentação, que está sendo aplicada aos poucos, notamos que a comunicação entrou em dilema, pois à medida que isso se tornou prática no cotidiano da gestão educacional, criando e desenvolvendo uma posição exclusiva e sustentável nos processos de Gestão da EaD, o presencial foi ficando distante, e com essa metodologia o comunicador físico deixou de estar presente, restando somente a virtualização. 
Destacando a importância de gerenciar novos recursos tecnológicos e pessoais para tal ação, a comunicação entra como fator decisivo nesse contexto de complexidade, pois não podemos olhar o todo sem esquecer as partes. E a construção dessa metodologia requer uma atenção que priorize, além do aprendizado em comum, métodos que auxiliem na transmissão de conteúdos para que sejam compreendidos, assimilados e aceitos pelos acadêmicos. É de responsabilidade do gestor desse processo esclarecer e formar meios que demonstrem como será construído o material didático de forma clara e concisa, como se pode ver na Figura 1:

\section{Construção do Material Didático}

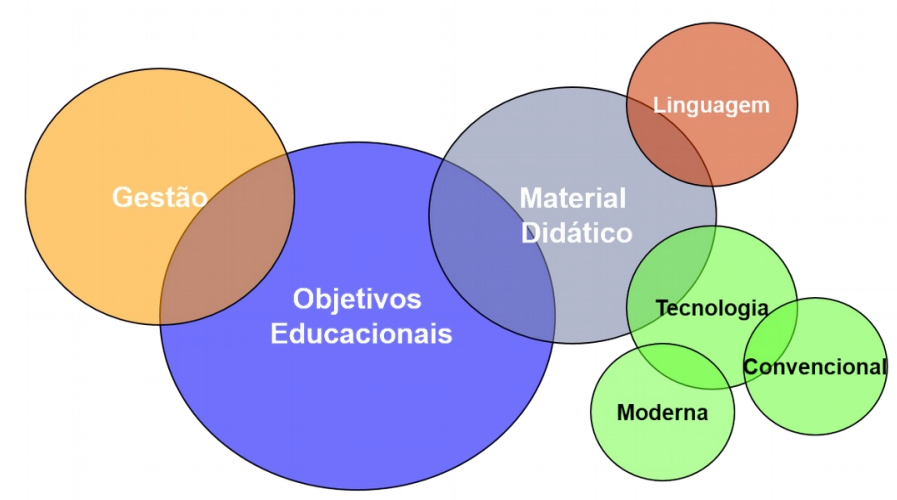

Figura 1: Construção de material didático.

Fonte: Martha Gabirel (2013).

Esse gerenciamento faz um link com algumas vertentes, tal qual a educação e a tecnologia, evidenciando, assim, a complexidade e a comunicação como fatores propulsores da virtualização de recursos didáticos pedagógicos. Morin (2011) afirma que o incremento do pensamento complexo, deve passar por uma reforma do pensamento por meio do ensino transdisciplinar, apropriada para formar cidadãos planetários, solidários e éticos, aptos a enfrentar os desafios dos tempos atuais, proporcionando desafios e questionamentos contínuos na Era da Informação.

A virtualidade passou a fazer parte do cotidiano dos acadêmicos e professores, gerando novas ferramentas e desafios a serem criados e questionados, para que essa infinita gama de informações seja rotina, e se torne um aprendizado mútuo, levando a comunicação e a complexidade a entrelaçarem-se e construir, dessa forma, um novo paradigma. 
No caso das questões que norteiam a educação e a tecnologia, em que utilizamos a virtualidade como aliada e não mais como um instrumento recluso, esse processo nos mostra que estamos a caminho de uma estruturação, o que já podemos constatar em grandes universidades que têm um amplo centro de ensino em EaD, no qual alunos de todas as partes têm acesso aos cursos e às vantagens de se estudar em qualquer lugar do mundo, com a mesma qualidade da modalidade presencial.

\section{RESULTADOS ESPERADOS}

A atual conjuntura educacional permite o surgimento de vertentes que irão possibilitar o maior desdobramento e aprendizado. Isso tem sido demonstrado pelos avanços tecnológicos e pela necessidade de acompanharmos tais mudanças, sejam elas de mercado, ou do público que também as constatam. Do ponto de vista de mercado, percebe-se que as IES que não acompanharem essas tecnologias em seu processo educacional irão perder espaço para as concorrentes, pois essa demanda tem crescido em âmbito nacional, proporcionando redução de custos, sem exigir a presença constante de seus acadêmicos em dias letivos.

Consideramos, assim, que tal qual a modalidade de ensino presencial, a EaD constrói-se com uma identidade própria e forte, com alunos, professores e entidades identificando-se com os novos papéis e funções sociais significativas na construção dos conhecimentos advindos das disciplinas ofertadas, gerando uma comunicação contemporânea que se faz de modo on-line por meio da virtualização, que se torna parte deste processo educacional e comunicacional.

Do ponto de vista da complexidade, percebemos que os processos tecnológicos e comunicacionais tendem a se tornar mais evidentes em grandes instituições, pois afinal, elas já deixaram de ser novidade e passaram a ser regra, até mesmo atividade contínua. Eis, então, uma necessidade, uma nova demanda que cabe aos multiplicadores dessas ferramentas exercerem uma função que possibilite a realização do aprendizado e o instigar de uma era que já faz parte do cotidiano de todos aqueles que lidam com computadores em rede, tablets, smarphones e com o mundo tecnológico em geral, pois esses instrumentos se tornarão, cada vez mais, presentes em sala de aula. 
A virtualização, como ferramenta comunicacional; seus fatores complexos, como foco deste artigo; além dos estudos desenvolvidos pelo Programa de Ciências da Comunicação (PPGCCOM) da Universidade Federal do Amazonas (UFAM), são de suma importância para que compreendamos esses entrançados existentes entre a comunicação e a complexidade, pois tudo pode se agregar de forma tal que não existam mais barreiras para educação, comunicação e aprendizado. Portanto, esperamos que as instituições que adotarem a modalidade EaD ou, pelo menos, a virtualização de algumas disciplinas já propostas em resoluções do Ministério da Educação, consigam acompanhar e desenvolver essa inovação com êxito, aplicando os conhecimentos de forma adequada, com o intuito de melhorar o ensino, bem como a aprendizagem do nosso país.

\section{REFERÊNCIAS}

CASTELLS, M. A Era da Informação: Economia, Sociedade e Cultura - Volume I: A Sociedade em Rede. São Paulo: Ed. Paz e Terra, Tradução de Roneide Venancio Majer.1999

CHIZZOTTI, A. Pesquisa qualitativa em ciências humanas e sociais. 3.ed. Petrópilis, RJ: Vozes, 2010.

CRESWELL, J.W. Projeto de Pesquisa: método qualitativo, quantitativo e misto. 3.ed. Porto Alegre: Ateneu, 2010.

DRUCKER, P. Administração por Objetivos. Saraiva ,São Paulo : 2000.

GABRIEL, M. Educar a revolução digital na educação. São Paulo: Saraiva , 2013.

GARCIA, M. A Rede mundial de computadores. In: Homodigitaliens. Autor: Marcos Coutinho. Out.2003 Disponível em:

<http://www.vetorial.net/ homodigitaliens/Pag1.htm>. Consultado em: 12mai.2015.

LÉVY, P. Do hipertexto opaco ao hipertexto transparente. In: $3^{\circ}$ Simpósio hipertexto e tecnologias na educação. Recife 2 a 3 de dezembro de 2010. Disponível em: $<$ http://www.youtube.com/watch?v=I9BUaMGKUuU\&feature=related $>$. Consultado em: 05Jan.2015.

. Educação e Cibercultura. Disponível em:

<http://empresa.portoweb.com.br/pierrelevy/educaecyber.html>. Acesso em: 24set.2002. 
$\overline{\text { Ed.34,1999. }}$

Cibercultura. Tradução de Carlos Irineu da Costa. São Paulo:

LEMOS, A. Cibercultura: Tecnologia e vida social na cultura contemporânea. 6.ed. Porto Alegre: Sulina , 2013.

LANDIM, C. M. F. Educação a distância: algumas considerações. Rio de Janeiro, s/n, 1997.

MARCHIORI, M. Comunicação em interface com cultura. Marlene Marchiori (org.). São Caetano do Sul, SP: Difusão Editora, 2013.

MAIA, C.; MATTAR, J. ABC da EAD: a Educação a Distância hoje. São Paulo: Pearson Prentice Hall, 2007.

MORIN, E. Introdução pensamento complexo. Tradução de Eliane Lisboa. 4.ed. Porto Alegre: Sulina, 2011. 120p.

A cabeça bem-feita: repensar a reforma, reformar o pensamento tradução Eloá Jacobina. 8.ed. Rio de Janeiro: Bertrand Brasil, 2003.

PENTEADO, J. R. W. A técnica da comunicação humana. 13.ed. São Paulo: Pioneira ,1997.

.Ministério da Educação - MEC. Resolução Nº. 2, 2007. Disponível em: <http://portal.mec.gov.br/index.php? option=com_content\&view=article\&id=12710\&ltemid=866>. Acesso em: 28Jan.2015

PRETTI, O. Inícios e indícios de um percurso. Cuiabá: UFMT - NEAD, 1996.

TERRA, E. Linguagem, língua e fala. São Paulo, Scipione, 1997. 